REVISTA DE GEOCIÊNCIAS DO NORDESTE

Northeast Geosciences Journal

v. $6, \mathrm{n}^{\circ} 2(2020)$

ISSN: $2447-3359$

https://doi.org/10.21680/2447-3359.2020v6n2ID18685

\title{
GEOMORFOLOGIA DA PORÇÃO TERMINAL DO BAIXO CURSO DO RIO PARAIÍBA DO NORTE-PB
}

\section{Larissa Fernandes de Lavor' ${ }^{1}$; Vinicius Ferreira de Lima²; Magno Erasto de Araújo ${ }^{3}$; Virginio Henrique de Miranda Lopes Neumann ${ }^{4}$}

${ }^{1}$ Doutoranda em Geociências, Centro de Tecnologia e Geociências, Universidade Federal de Pernambuco (UFPE), Recife - PE, Brasil.

ORCID: https://orcid.org/0000-0001-7607-440X

Email: larylavor@hotmail.com

${ }^{2}$ Doutorando em Geografia, Universidade Federal da Paraíba (UFPB), Centro de Ciências Exatas e da Natureza, João Pessoa $\mathrm{PB}$, Brasil.

ORCID: https://orcid.org/0000-0001-5338-3031

Email: viniciusgeo_lima@hotmail.com

${ }^{3}$ Doutor em Arquitetura e Urbanismo, Centro de Ciências Exatas e da Natureza, Universidade Federal da Paraíba (UFPB), João Pessoa - PB, Brasil.

ORCID: https://orcid.org/0000-0003-4538-133X

Email: magnoerasto@gmail.com

${ }^{4}$ Doutor em Análise de Bacias Sedimentares, Centro de Tecnologia e Geociências, Universidade Federal de Pernambuco (UFPE), Recife - PE, Brasil.

ORCID: https://orcid.org/0000-0002-8827-6022

Email: virginio.neumann@ufpe.br

\section{Resumo}

Este trabalho objetiva compreender o quadro geomorfológico da porção terminal do baixo curso do rio Paraíba do Norte - PB, mediante a classificação e diferenciação cartográfica das unidades de relevos presentes na área de estudo. Adotou-se para o presente trabalho a escala de 1:25.000 que permitiu identificar os seis táxons propostos na metodologia de Ross (1992). O estudo possibilitou conhecer com maior nível de detalhe a geometria e os padrões de relevo existentes na região, onde se destacaram áreas de acumulação e denudação, dentre elas: planícies marinhas, fluviais e flúvio marinhas, formas de terraços e vertentes, falésias, praias, barras arenosas, bancos de areia, paleolinhas de praias, recifes, lagoas antropogênicas, lagunas, dolinas e glacis de sedimentação, além de formas de relevos tabulares e convexos que modelam os tabuleiros litorâneos da costa paraibana.
Palavras-chave: Geomorfologia; Litoral paraibano; Estuário do rio Paraíba do Norte-PB.

\section{GEOMORPHOLOGY OF THE TERMINAL PORTION OF THE LOWER COURSE OF THE PARAÍBA DO NORTE- PB RIVER}

\begin{abstract}
This work aims to understand the geomorphological framework of the terminal portion of the lower course of Paraíba do Norte river- PB, through the classification and cartographic differentiation of the relief units present in the study area. For the present work, a scale of 1: 25,000 was adopted, which allowed identifying the six taxons proposed in Ross's methodology (1992). The study made it possible to know in greater detail the geometry and relief patterns in the region, where stood out accumulation and denudation areas, among them: fluvial, marine and fluvial-marine plains, terrace shapes and slopes, cliffs, beaches, sandy bars, sandbanks, beach paleolines, reefs, anthropogenic lagoons, lagoons, sink holes, and sedimentation glacis, besides tabular and convex relief forms that shape the coastal boards of the Paraíba coast.
\end{abstract}

Keywords: Geomorphology; Paraíba Coast; Paraíba do NortePB Riverestuary.

\section{GEOMORFOLOGÍA DE LA PORCIÓN TERMINAL DEL CURSO INFERIOR DEL RÍO PARAÍBA DO NORTE-PB}

\section{Resumen}

Este trabajo objetiva comprender la imagen geomorfológica de la porción terminal del curso inferior del río Paraíba do Norte - PB, mediante la clasificación y diferenciación cartográfica de las unidades de relieve presentes en el área de estudio.Se adoptó una escala de 1:25,000 para el presente trabajo, lo que permitió la identificación de los seis taxones propuestos en la metodología de Ross (1992). El estudio permitió conocer con mayor detalle la geometría y los patrones de relieve existentes en la región, donde se destacaron las áreas de acumulación y denudación, entre ellas:llanuras marinas, fluviales y fluviomarinas, formas de terrazas y vertientes, acantilados, playas, barras arenosas, bancos de arena, paleolinas, arrecifes, estanques antropogénicos, lagunas, dolinas y glacis de sedimentación, además de formas de relieves tabulares y convexos que modelan los TablerosLitráneos de la costa de Paraíba. 
Palabras-clave: Geomorfología; Costa de Paraíba; Estuario del río Paraíba do Norte-PB.

\section{INTRODUÇÃO}

A geomorfologia detalhada de uma área possibilita conhecer, com maior nível de detalhe, o relevo e a geometria dos padrões de drenagem da região, revelando o potencial natural existente na área, facilitando a identificação de áreas de risco, ambientes frágeis, impactos ambientais, interferência antrópica e dinâmica da evolução natural da paisagem. O objetivo deste trabalho é compreender o quadro geomorfológico da porção terminal do baixo curso do rio Paraíba do Norte - PB, classificando e mapeando as unidades de relevo. Entende-se por porção terminal do baixo curso do rio Paraíba do Norte a área correspondente aos terrenos dos tabuleiros litorâneos e planícies marinhas onde se encontram sistemas deposicionais, fluviais, estuarinos, praiais e marinhos rasos.

Segundo Maia e Bezerra (2012), o estudo do relevo por meio de bases cartográficas e metodologias específicas extraídas da Geomorfologia, da Geologia, da Matemática e do Geoprocessamento, torna-se um meio eficaz de averiguação e análise do padrão morfológico resultante da interface entre os agentes endógenos e exógenos.

$\mathrm{Na}$ presente pesquisa, tem-se um direcionamento aos estudos geomorfológicos tomando como base os pressupostos estabelecidos pelas diretrizes da Geomorfologia Geral, considerando a influência direta da estrutura geológica e da tectônica na configuração atual do relevo, que pode ser representada pela cartografia geomorfológica. Nesse contexto, os mapeamentos temáticos se tornam essenciais em Geomorfologia, principalmente, para o planejamento físico-ambiental, já que a espacialização e localização dos fatos permitem representar e compreender as formas do relevo e a dinâmica dos processos atuantes (ROSS, 1992; MARQUES, 2007; RODRIGUES; OLIVEIRA, 2007).

No mapeamento geomorfológico, a noção e o cuidado que se deve direcionar para o conceito de escala é imprescindível. Autores como Ross (2014) e Christofoletti (1980) destacam a importância da escala no tratamento e representação do relevo no grau de detalhamento ou de generalização da informação, pois é a escala que vai determinar a adoção de diferentes estratégias e técnicas de abordagem. Por exemplo, as cartas com grande escala permitem mapear formas de relevo locais mais pontuais, evidenciando os processos atuais e antrópicos na elaboração do modelado, enquanto os mapas de menor escala permitem mapear grandes extensões areais, (BRASIL, 2009; ROSS, 1992).

Assim, de acordo com esse entendimento, adotou-se para o presente trabalho a escala de detalhe de 1:25.000, cujos produtos finais foram publicados na escala de 1:80.000. A escolha da escala de 1: 25.000 se justifica pela ótima quantidade e qualidade de detalhes, permitindo identificar os seis táxons propostos na metodologia de Ross (1992).

Para Souza (2015), "devido ao déficit de mapeamentos planialtimétricos, em grandes e médias escalas, no Brasil [...], há uma dificuldade na obtenção e processamento de informações topográficas nessas escalas". No entanto o emprego das novas tecnologias e a disponibilidade de Sistemas de Informação Geográfica (SIGs), gratuitos, tem se tornado cada vez mais usual, permitindo a elaboração desses produtos cartográficos. Como exemplo pode-se citar os trabalhos elaborados por Rodrigues e Oliveira (2007), Barbosa, Furrier e Souza (2018), que vêm desenvolvendo mapeamentos geomorfológicos associados às características estruturais do terreno resultando em uma avaliação detalhada da área, uma vez que os produtos gerados viabilizam a representação dos elementos geomorfológicos e ampliam o entendimento das peculiaridades do relevo.

Nesta mesma perspectiva, a presente pesquisa oferece informações detalhadas do relevo trazendo resultados inéditos para a área de estudo com dados confiáveis, haja vista que as cartas topográficas utilizadas como base foram produzidas por aerolevantamento planialtimétrico com apoio em solo, com um detalhamento elevado. Dessa forma, foi possível elaborar mapas temáticos e modelos escalares particularizados das unidades geomorfológicas que permitiram o entendimento das relações entre o relevo e o padrão litológico, realçando as feições resultantes da interface entre ambos, que, associados, dão origem à configuração física da área.

\section{CARACTERIZAÇÃO DA ÁREA DE ESTUDO}

A área estudada delimita-se por uma poligonal que abrange a porção terminal do baixo curso do rio Paraíba do Norte - PB, entre as coordenadas planas UTM $9.231 .000 \mathrm{mN}$ a $9.211 .000 \mathrm{mN}$ e $291.000 \mathrm{mE}$ a $301.000 \mathrm{mE}$, Datum SIRGAS 2000, zona 25S (Figura 1), recobrindo o município de Cabedelo e parte dos municípios de Lucena, Santa Rita, Bayeux e João Pessoa.

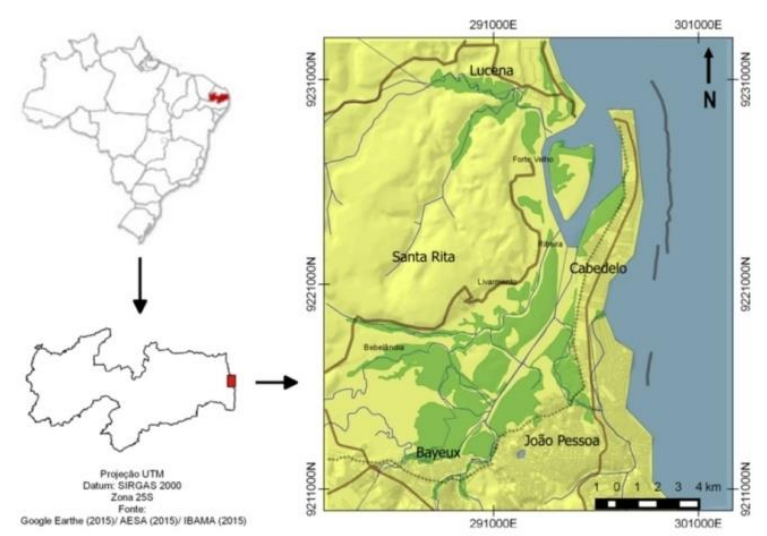

Figura 1 - Localização da área de estudo. Fonte: Lavor (2016). Nota: delimitação do estuário do rio Paraíba do norte na cor verde; A cor amarela representa os terrenos dos Tabuleiros Litorâneos e Planícies Marinhas da área.

A área se insere na porção centro-oriental da Bacia Paraíba, que é preenchida por sedimentos de fácies continentais e marinhas, reunidas sob a denominação de Grupo Paraíba, que, por sua vez, é subdividido em cinco Formações: Beberibe, Itamaracá, Gramame, Maria Farinha e Tambaba (BRASIL, 2002; CORREA FILHO et al., 2015), sendo constituída de arenitos médios, grossos e conglomeráticos de origem continental, e as demais de deposições carbonáticas. Capeando o Grupo Paraíba, porém não fazendo parte dele, está a Formação Barreiras, de origem continental. Essa Formação consiste na unidade litoestratigráfica 
mais contínua ao longo do litoral brasileiro, ocorrendo desde o Estado do Pará até o Rio de Janeiro. Ela se caracteriza pela presença de fácies de um sistema fluvial entrelaçado e transicional para leques fluviais, de depósitos granulométricos variados, apresentando cascalhos, areias grossas e finas de coloração amarelada, com intercalações de siltes e argilas (ALHEIROS et al., 1988).

Sobre a Formação Barreiras e/ou constituindo os níveis mais superficiais de toda a área estudada, localizam-se os sedimentos pleistocênicos e holocênicos, que constituem os depósitos eluvionares, coluvionares e aluvionares (Figura 2, Tabela 1) e respondem pela formação das areias brancas que recobrem os tabuleiros, das vertentes, dos manguezais, das praias atuais etc. Nessas unidades litoestratigráficas são esculpidos os tabuleiros litorâneos, conjuntamente com as planícies costeiras e fluviais, que juntos constituem os três maiores compartimentos do relevo da área estudada. Os tabuleiros geralmente apresentam topos aplainados, ora soerguidos, ora rebaixados ou basculados por evidente atuação da tectônica recente (FURRIER; ARAÚJO; MENESES, 2015).

Em termos de cobertura areal, as litologias predominantes na área são, respectivamente, representadas pela Formação
Barreiras, que ocupa uma superfície de $121,38 \mathrm{~km}^{2}$, o que corresponde a $28,88 \%$ do total da área estudada (Figura 2, Tabela 1). Os sedimentos coluvionares ocupam $53,71 \mathrm{~km}^{2}$ ou $12,78 \%$ da área e consistem de material decorrente da alteração e transporte da Formação Barreias. Os sedimentos Aluvionares, praiais, e de mangue, juntos, ocupam $138,09 \mathrm{~km}^{2}$ ou $32,86 \%$ do terreno. As rochas mais antigas aflorantes na região correspondem aos carbonatos de idade cretácica, com superfície de 0,48\%. Esses afloramentos ocorrem predominantemente nas bases das vertentes voltadas para oeste do município de João Pessoa, e quando se localizam nas porções mais a leste, no município de Santa Rita, afloram em grandes superfícies em nível de solo (Figura 2 e Tabela 1). Estudos afirmam que os calcários localizados no município de João Pessoa pertencem à Formação Gramame, enquanto que no município de Santa Rita há incertezas se eles correspondem à base da Formação Gramame ou aos calcarenitos pertencentes à Formação Itamaracá (LAVOR; ARAÚJO, 2016).

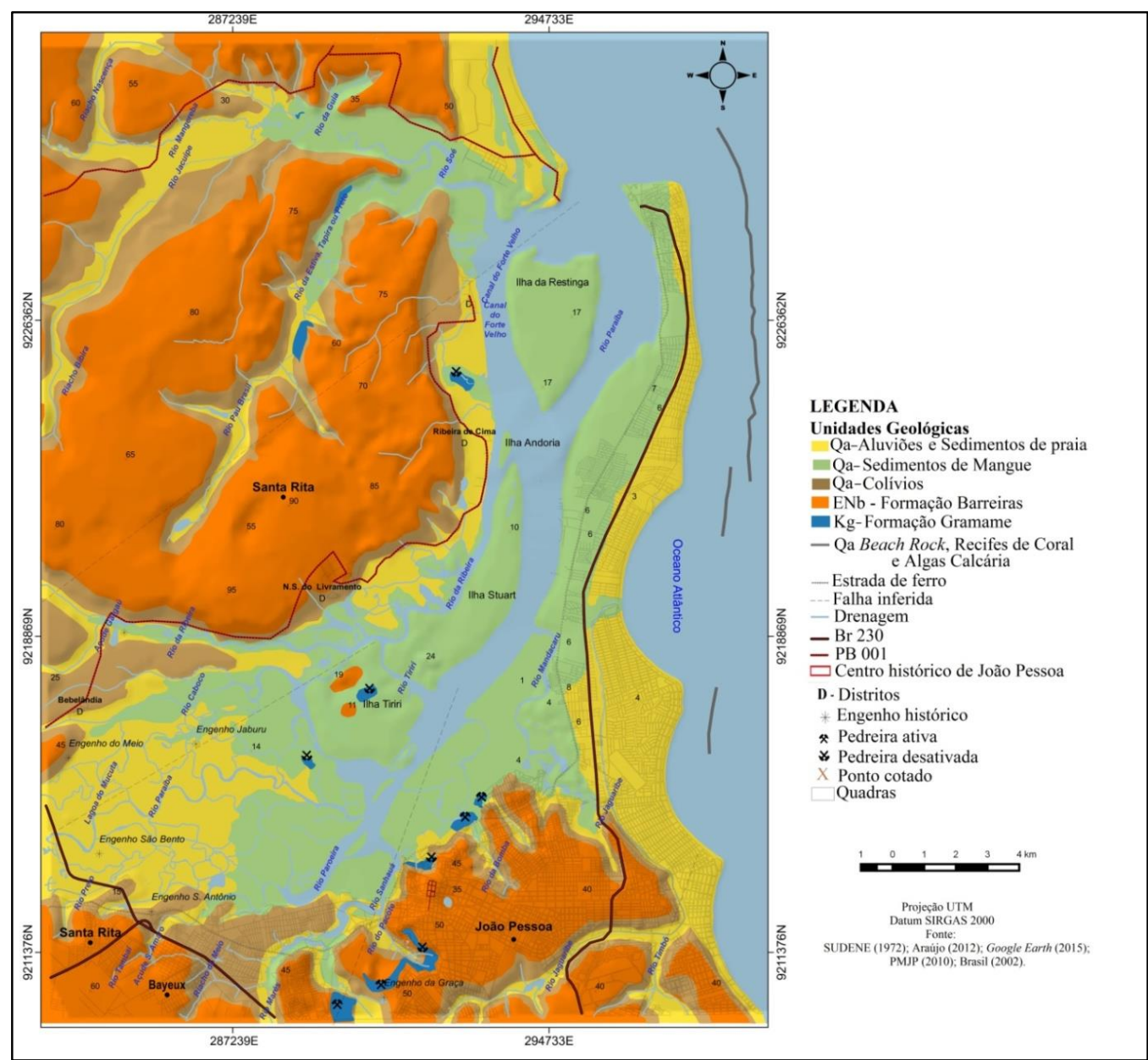

Figura 2 - Mapa geológico da região do estuário do rio Paraíba do Norte - PB. Fonte: Lavor (2016). 
Tabela 1 - Unidades superficiais da área estudada em $\mathrm{km}^{2}$ e percentual. Fonte: Lavor (2016).

\begin{tabular}{lcc}
\hline \multicolumn{1}{c}{ Classes } & Áreas em K $\mathbf{~ m}^{\mathbf{2}}$ & Áreas em \% \\
\hline Formação Barreiras & 121,38 & $28,88 \%$ \\
Aluviões e Sedimentos de praia & 102,46 & $24,38 \%$ \\
Coluviões & 53,71 & $12,78 \%$ \\
Calcários (Formação Gramame e Itamaracá) & 2,00 & $0,48 \%$ \\
Sedimentos Mangue & 35,63 & $8,48 \%$ \\
Recifes & 11,00 & $2,62 \%$ \\
Água & 94,07 & $22,38 \%$ \\
\hline Total & $\mathbf{4 2 0 , 2 5}$ & $\mathbf{1 0 0 , 0 0 \%}$ \\
\hline
\end{tabular}

\section{MATERIAIS E MÉTODOS}

O desenvolvimento deste trabalho ocorreu de acordo com as seguintes etapas:

a) Revisão bibliográfica/documental/cartográfica e organização dos dados existentes: nesta etapa, obtiveram-se dados precedentes, como: publicações sobre a geologia da Bacia Sedimentar Paraíba (sedimentação, tectônica e estrutura) e a geomorfologia; mapa geológico e geomorfológico do estado da Paraíba, escala 1:500.000 (BRASIL, 2002) disponível em meio digital pela Agência Executiva de Gestão das Águas do Estado da Paraíba (Aesa); mapa geológico da folha SB25-Y-A-VII (Cabedelo), escala 1:100.000 (NEUMANN et al., 2014), disponível no Geobank da Companhia de Pesquisa de Recursos Minerais (CPRM); imagens de satélite do Google Earth; e as cartas topográficas da Superintendência de Desenvolvimento do Nordeste (Sudene) de 1972, em escala 1:25.000, folhas: SB.25Y-A-VI3-SE (Cabedelo), SB.25-Y-A-VI-3-SO (Rio Soé), SB.25Y-C-III-1-NE (João Pessoa), SB.25-Y-C-III-1-NO (Mata da Aldeia) e SB.25-Y-C-III-1-SO (Santa Rita) (BRASIL, 1972).

b) Interpretações temáticas prévias: em laboratório foram selecionados os atributos a serem utilizados na interpretação geomorfológicas como, curvas de nível, drenagem e pontos cotados. Esses atributos foram extraídos das cartas topográficas previamente selecionadas no qual aplicou-se técnicas de processamentos gráficos (vetorização pontual, linear e poligonal) em um ambiente SIG. Em seguida procedeu-se a geração do modelo hipsométrico por meio do método de triangulação. $\mathrm{O}$ terceiro passo foi à geração do mapa clinográfico classificados de acordo com a metodologia da EMBRAPA (1997).

c) Levantamento de dados em campo: por meio das fontes bibliográficas e dos mapas previamente elaborados em laboratório, foi possível preparar uma relação de dados a serem investigados no campo. As coletas de dados ocorreram ao longo de idas à área de estudo, no intuito de identificar e posicionar os elementos morfológicos elencados na relação, mediante registros fotográficos, criação de perfis topográficos manuais e aquisição de pontos estratégicos coletadas por um global positioning system (GPS).

d) Integração dos dados e elaboração dos produtos cartográficos: elaborou-se o mapa geomorfológico seguindo a metodologia para mapeamento de Ross (1992), com adaptações de Furrier (2007), que ajustou a metodologia para áreas de relevos predominantemente tabular. Essa metodologia propõe seis níveis de unidade de relevos, classificados como: $1^{\circ}$ táxon: refere-se à morfoestrutura da bacia sedimentar, que, por meio de suas características estruturais, define padrões de formas grandes do relevo;

$\mathbf{2}^{\circ}$ táxon: consiste nas unidades morfoestruturais, formadas pela ação climática ao longo do tempo geológico;

$3^{\circ}$ táxon: corresponde às unidades de padrão das formas de relevos semelhantes. É neste táxon onde os processos morfoclimáticos atuais podem ser observados;

$4^{\circ}$ táxon: são os tipos de formas de relevo individualizados no interior das unidades de padrão e formas de relevos semelhantes. Essas formas podem estar relacionadas a processos de agradação (acumulação) ou denudação. Neste trabalho, utilizaram-se seis classes de acumulação baseadas nas nomenclaturas sugeridas por Furrier (2007) para a caracterização do quarto táxon, a saber: (a) área de terraço e planície marinha (Atpm); (b) área de planície fluviomarinha (Apfm); (c) área de colúvio, terraço e planície fluvial (Actpf); (d) área de colúvio, terraço e planície fluviomarinha (Actpfm); (e) área de colúvio, terraço e planície marinha (Actpm); e (f) área de terraço e planície fluvial (Atpf). Quanto às formas de denudação, estas se dividem em dois tipos: formas tabulares e convexas (ROSS, 1992). Dentro delas, há uma subdivisão que se baseia na morfometria obtida entre a dimensão interfluvial média e o grau de entalhamento dos vales (Tabela 2);

$5^{\circ}$ táxon: corresponde às formas individualizadas do relevo, cujo contorno pode ser convexo, retilíneo ou côncavo. São consideradas as vertentes ou setores das vertentes pertencentes a cada uma das formas individualizadas do relevo.

$6^{0}$ táxon: corresponde às formas de relevo menores, geradas pelos processos erosivos atuais ou por depósitos atuais. . É nesse táxon que podem ser representadas formas de relevo geradas pela ação humana, como: mineração, cortes de vertentes, dentre outras. 
Tabela 2 - Matriz dos índices de dissecação das formas de relevo. Fonte: Adaptado de (ROSS, 1992).

\begin{tabular}{|c|c|c|c|c|c|}
\hline \multirow[b]{2}{*}{$\begin{array}{c}\text { Grau de entalhamento } \\
\text { dos vales }\end{array}$} & \multicolumn{5}{|c|}{ Dimensão interfluvial média } \\
\hline & $\begin{array}{c}\text { Muito } \\
\text { grande }(1)> \\
1.500 \mathrm{~m}\end{array}$ & $\begin{array}{c}\text { Grande (2) } \\
1.500 \text { a } 700 \mathrm{~m}\end{array}$ & $\begin{array}{c}\text { Média (3) } \\
700 \text { a } 300 \mathrm{~m}\end{array}$ & $\begin{array}{l}\text { Pequena (4) } \\
300 \text { a } 100 \mathrm{~m}\end{array}$ & $\begin{array}{c}\text { Muito pequena } \\
\text { (5) } \\
\leq 100 \mathrm{~m}\end{array}$ \\
\hline Muito fraco $(1)<20 \mathrm{~m}$ & 11 & 12 & 13 & 14 & 15 \\
\hline Fraco (2) $20-40 \mathrm{~m}$ & 21 & 22 & 23 & 24 & 25 \\
\hline Médio (3) $40-80 \mathrm{~m}$ & 31 & 32 & 33 & 34 & 35 \\
\hline Forte (4) $80-160 \mathrm{~m}$ & 41 & 42 & 43 & 44 & 45 \\
\hline Muito forte $(5)>160 \mathrm{~m}$ & 51 & 52 & 53 & 54 & 55 \\
\hline
\end{tabular}

\section{RESULTADOS}

\subsection{Padrões e tipos de relevos}

Os tabuleiros litorâneos recebem essa designação por apresentarem topografias de terrenos relativamente planos. $\mathrm{Na}$ área de estudo, esse padrão de relevo possui cotas altimétricas de até $95 \mathrm{~m}$ em relação ao nível do mar. Estudos apontam que a neotectônica de microescala ocorrida no Quaternário fez com que esses tabuleiros se reestruturassem, de modo a parecerem como um "teclado de piano", onde se verificam notáveis desníveis altimétricos, associados a vales encaixados (FURRIER; ARAÚJO; MENESES, 2015; SUGUIO, 2012).

É possível que, em função dessa neotectônica, os topos desses tabuleiros (Figura 3) tenham gerado formas de denudações tabulares (Dt) de três níveis e formas de denudações convexas (Dc) de um nível, que são:

Dt31: Elas são observadas nos tabuleiros de João Pessoa, Santa Rita e Lucena, envolvendo 13,31\% da área de estudo, o que equivale a 55,95 km² (Figura 3). Em João Pessoa, essas áreas estão relacionadas às cotas altimétricas de até $50 \mathrm{~m}$. São tabuleiros amplos, relativamente planos e com uma rede hidrográfica pouco densa. Em Santa Rita e em Lucena, a forma de relevo tabular Dt31 está relacionada a cotas altimétricas de até $60 \mathrm{~m}$. É constituída de tabuleiros amplos, relativamente planos, com uma rede hidrográfica pouco densa. Esses tabuleiros encontram-se bastante dissecados e basculados na direção nortesul.

Dt32: Esse tipo de relevo é observado nos tabuleiros de Bayeux, entre os rios Marés e Preto, e Santa Rita, próximo ao Engenho Santana (Figura 3), ocupando 10,73 km² (2,55\%) da área de estudo. No município de Bayeux, esses tabuleiros possuem cotas altimétricas de até $60 \mathrm{~m}$, são constituídos de terrenos quase planos, com rede hidrográfica pouco densa e basculado para leste. A forma de relevo Dt32 também ocorre no município de Santa Rita, em sua área rural. Ela está relacionada a cotas altimétricas de até $45 \mathrm{~m}$, representando os tabuleiros mais baixos da área de estudo.

Dt41: Esse tipo de relevo é observado no tabuleiro de Santa Rita. Essa unidade ocupa 47,22 km² $(11,24 \%)$ da área de estudo. Suas cotas altimétricas vão até $80 \mathrm{~m}$, constituído de topo relativamente plano a semicolinoso. Esses tabuleiros encontramse basculados para nordeste e são constituídos por uma rede hidrográfica pouco densa e com vales fluviais aparentemente desenvolvidos nas zonas de fratura (Figura 3).
Dc31: Esse relevo localiza-se no tabuleiro de Santa Rita, ao lado direito da nascente do rio Pau-Brasil até as imediações do distrito de Livramento, ocupando, aproximadamente, 7,48 km² $(1,78 \%)$ de extensão (Figura3). É nesse trecho que se observa a cota mais alta da área de estudo, que corresponde a $95 \mathrm{~m}$. Tanto as formas de relevos Dt41 com a Dc31, localizam-se no tabuleiro de Santa Rita e devido à presença de áreas que aparentemente sofreram subsidência, formam depressões semicirculares no local.

Além dos tabuleiros litorâneos, a área também é formada por planícies que se configuram como áreas de acumulação ou deposição de sedimentos. Sendo assim, foram identificados seis tipos de formas de acumulação na porção terminal do baixo curso do rio Paraíba do Norte, que são:

a) Área de Acumulação de terraços e planícies marinhas (Atpm)

Localizam-se na zona de praia e de cristas praiais e ocupam $31,56 \mathrm{~km}^{2}(7,51 \%)$ da área de estudo, com cotas altimétricas baixas, variando entre 0 a $8 \mathrm{~m}$ (Figura 3 ). No que se referem às planícies marinhas (Quadro 1a), estas podem ser classificadas como as áreas de praias que ainda sofrem com a ação das ondas, enquanto que os terraços marinhos estão representados por um conjunto de antigas linhas de costas, que, segundo Suguio (1998), representam antigos relevos costeiros, situados acima ou abaixo do nível do mar atual, equivalente a paleolinhas praiais. Geograficamente, a forma de relevo Atpm situa-se na direção leste da área de estudo (Figura 3), mais precisamente na orla dos municípios de João Pessoa; Cabedelo e Lucena (Figura 4a).

\section{b) Área de Acumulação de colúvios, terraços e planícies} marinhas (Actpm)

Ocupa $0,58 \mathrm{~km}^{2}(0,14 \%)$ da área de estudo. É a unidade geomorfológica de menor extensão territorial, porém, com uma representatividade significativa no que diz respeito à caracterização geomorfológica do litoral paraibano (Figura 3). Nessa unidade, aparecem as falésias marinhas (ativas e inativas), responsáveis pela típica paisagem que se forma nas praias do Nordeste brasileiro (Quadro 1b e 1c). Na área de estudo, os processos deposicionais costeiros e o ataque constante das ondas sobre as falésias promoveram seu recuo para oeste, tornando-as inativas em alguns trechos. Como exemplos têm-se as falésias do setor leste do município de João Pessoa, nos bairros de Tambaú e Manaíra, e a praia de Fagundes em Lucena.

\section{c) Área de Acumulação de planície flúvio marinha (Apfm)}

Corresponde às áreas de mangue e de restinga (Figura 3) e se localizam no trecho terminal dos baixos cursos dos rios, sendo formada por depósitos fluviais e marinhos. São áreas influenciadas pela oscilação das marés de sizígia, presente desde 
a desembocadura dos rios que deságuam no oceano até onde se faz vigente a ação das marés. É nesse trecho da área de estudo que se localiza o estuário e parte da Restinga de Cabedelo, com cotas altimétricas variando entre 0 a $5 \mathrm{~m}$. No seu interior, formam-se ilhas, a destacar: Tiriri, Stuart, Andorinha e da Restinga (Quadro 1d).O município de Cabedelo está inserido quase em sua totalidade nesse compartimento geomorfológico, que, em consórcio com a unidade de relevo Atpm, constitui área do município. Já no município de João Pessoa, a unidade de relevo Apfm ocorre na porção terminal dos rios que deságuam no oceano Atlântico e nas margens dos rios Sanhauá e Mandacaru (Figura 3). No total ocupam $40 \mathrm{~km}^{2}(9,52 \%)$ da área de estudo.

d) Área Acumulação de colúvio, terraço e planície flúvio marinha (Actpfm)

Localiza-se no setor centro-oeste da área de estudo (Figura 3) e ocupa $21,61 \mathrm{~km}^{2}(5,14 \%)$ de área, com cotas altimétricas variando de 5 a $30 \mathrm{~m}$. Ela inclui porções da planície flúvio marinha, dos terraços e dos colúvios que recobrem os sopés das vertentes dos tabuleiros de Santa Rita e Lucena. É nesse ambiente que se formam lagunas e afloram calcário na margem esquerda do rio Ribeira. Nesse trecho, a Actpfm estende-se por $1,5 \mathrm{~km}$, desde o sopé da vertente do tabuleiro de Santa Rita até a margem esquerda do rio Ribeira, onde se situam os distritos de Ribeira e Forte Velho.

e) Área de Acumulação de terraço e planície fluvial (Atpf)

Esse relevo ocupa uma área de $26 \mathrm{~km}^{2}(6,19 \%)$, com cotas altimétricas variando entre 0 a $14 \mathrm{~m}$, e constitui-se de planícies e terraços fluviais (Figuras 3 e Quadro 1e). A planície fluvial, também identificada como de inundação, corresponde à superfície pouco elevada localizada acima do nível médio da água do canal fluvial, logo após os diques marginais (GUERRA; GUERRA, 2008).

f) Área de Acumulação de colúvio terraço planície fluvial (Actpf)

Essa feição morfológica é encontrada em consórcio com a Atpf e estende-se por quase todas as vertentes dos tabuleiros litorâneos, ocupando uma área de 74 km² (17,61\%) (Figura 3). Nessa região se localizam os glacis ou pedimentos, que se projetam para jusante com fraca declividade, alimentando com sedimentos as calhas fluviais 


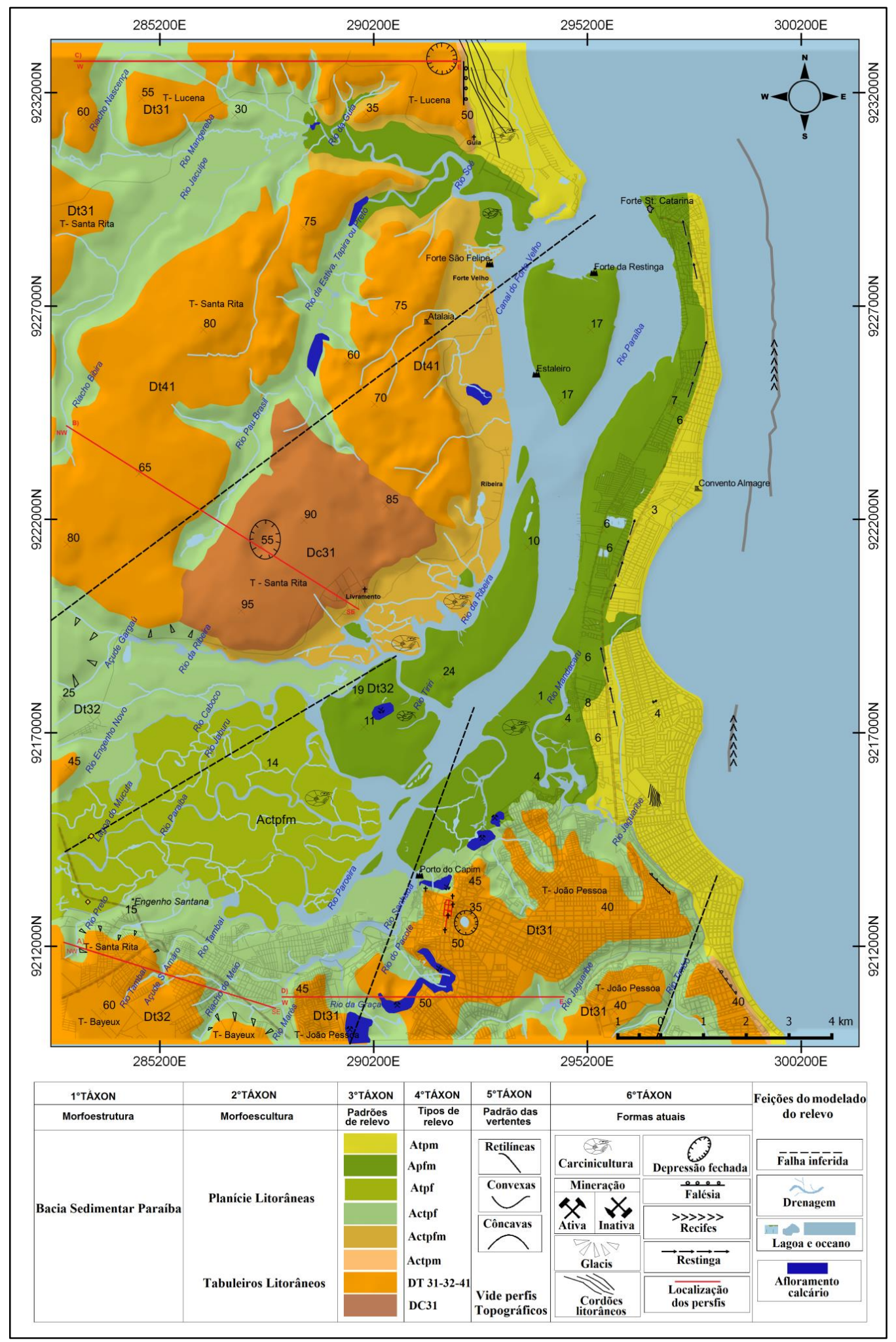

Figura 3 - Mapa geomorfológico da porção terminal do baixo curso do rio Paraíba do Norte. Fonte: Lavor (2016). 
Quadro 1 - Tipos de Revelo de acumulação presentes na área de estudo.

A) Área de terraços e planície marinha (Atpm) na praia Ponta de Lucena. Observa-se na fotografia aérea parte da planície marinha do município de Lucena, formada pela praia (1) e antepraia da Ponta de Lucena. Em seguida têm-se os terraços marinho Holocenos (3) contendo antigas linhas de costa (seta amarela) a oestes da imagem.

B) Falésia inativa da praia de Cabo Branco (João Pessoa). Observa-se na imagem um trecho da falésia inativa do Cabo Branco (linha amarela), que se estende até a praia de Manaíra, ao norte. A linha vermelha corresponde às áreas onde se depositaram sedimentos coluvinares e que nos dia atuais encontram-se sotopostos pela vegetação. Também se verifica a presença de terraços de abrasão (1) resultante da erosão ocorrida na falésia, indicando sua antiga posição e o recuo da vertente para oeste. O número 2 representa a faixa de praia do Cabo Branco.

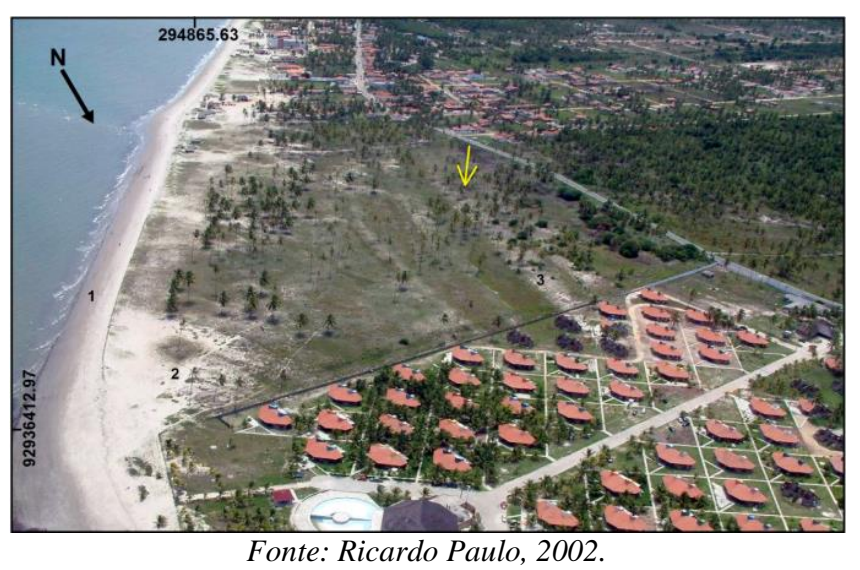

Fonte: Ricardo Paulo, 2002.

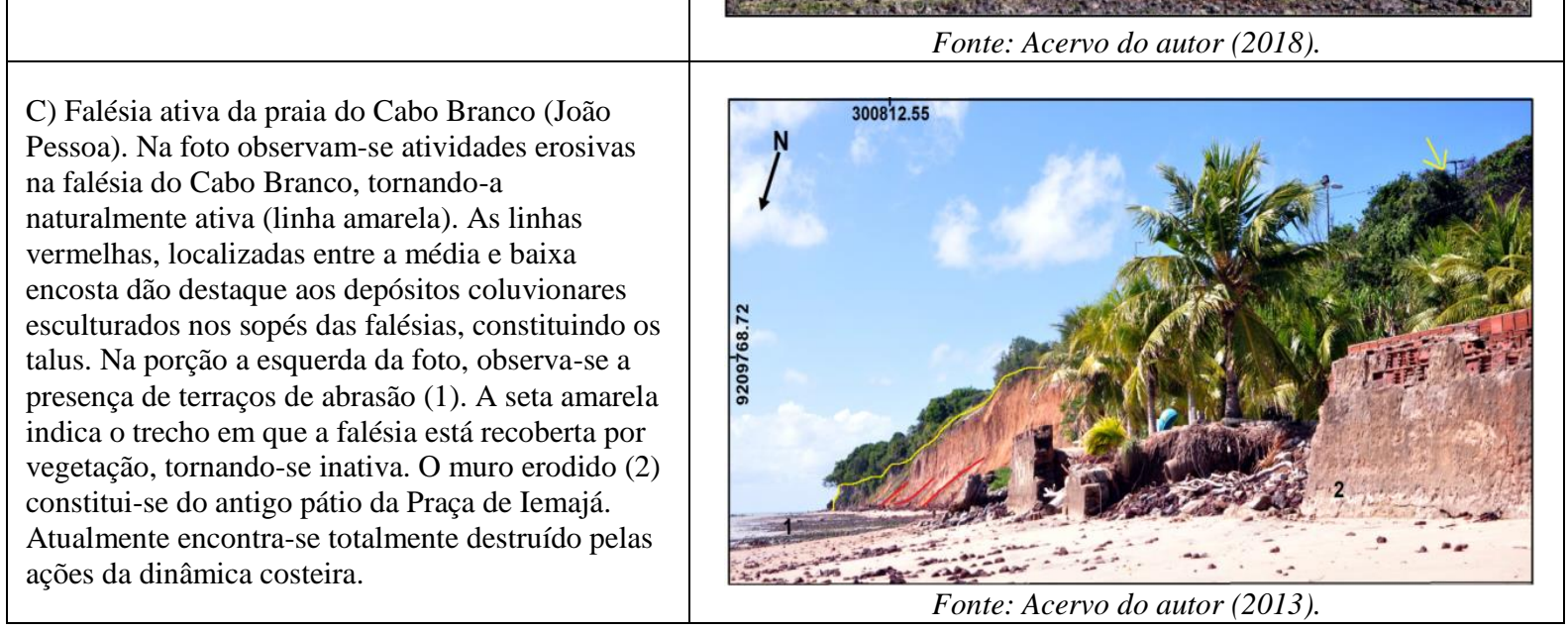




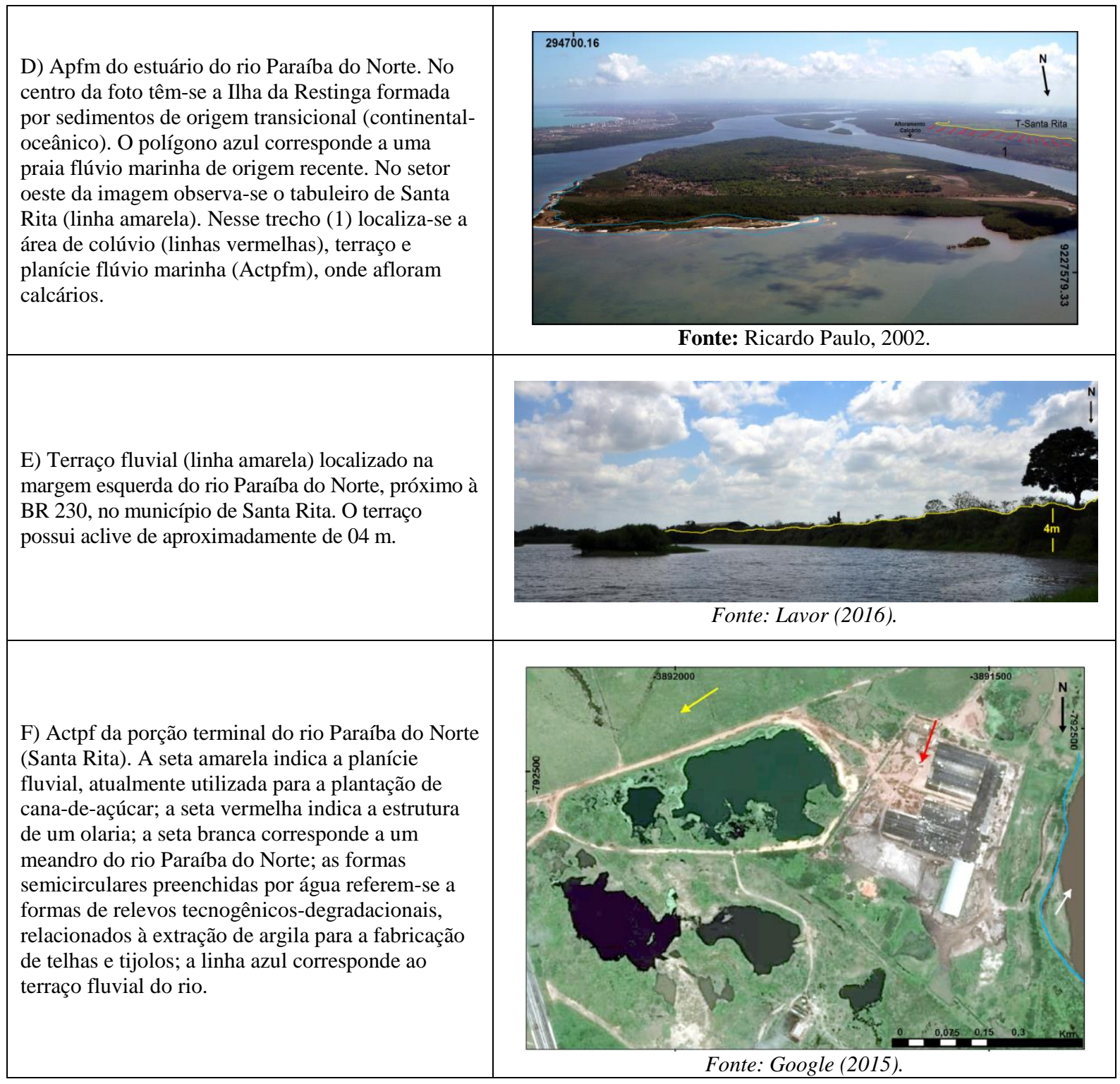

\subsection{Padrões e tipos de vertentes}

Considerando-se os processos responsáveis pela esculturação das encostas dos tabuleiros, dois grupos de vertentes podem ser evidenciados: as falésias, onde as dinâmicas continentais e marinhas se complementam na sua esculturação; e as vertentes dos vales fluviais, onde a dinâmica continental tem papel dominante. Para melhor ilustrar essas vertentes, foram elaborados perfis topográficos da área de estudo. Esses perfis permitiram caracterizar trechos dessas encostas (Figura 5).

Por meio de observações feitas em campo, verificou-se que as vertentes localizadas no município de Bayeux (Figuras 3 e $5 \mathrm{a}$ ) são do tipo: convexo-retilínea e retilíneo-convexa, formando vales de fundo côncavo, no rio Preto; encaixado e assimétrico, com vertente retilíneo-convexa na margem esquerda e retilíneocôncava na margem direita do rio Tambaí; e assimétrico, no riacho do Meio, com vertente convexo-retilínea na margem esquerda e retilíneo-côncava na margem direita.

No município de Santa Rita, verifica-se que as formas de vertentes (Figuras 3 e $5 b$ ) apresentam padrões do tipo: convexoretilínea, na margem esquerda do rio Jacuípe; vale em $\mathrm{V}$, na nascente do rio da Estiva; vale de fundo chato, com vertentes convexo-retilíneas, no rio Pau-Brasil; e vertentes do tipo convexo-retilínea, na encosta da margem esquerda do rio Ribeira. Além dos vales fluviais, esse perfil apresentou duas formas de relevo na superfície do tabuleiro. A primeira se constitui de um pequeno morro testemunho em forma de meseta (pequeno Platô), localizado entre o rio Jacuípe e a nascente do rio da Estiva; e a 
segunda corresponde a uma depressão fechada, localizada entre o rio Pau-Brasil e o rio Ribeira.

No município de João Pessoa, entre a vertente da margem direita do rio Marés e a vertente da margem esquerda do rio Jaguaribe, verificou-se, em campo, encostas do tipo convexo- retilíneas, o que evidencia formas de relevo do tipo meseta. A planitude desse tabuleiro é interrompida pelo entalhamento do rio da Graça e pela exploração de calcário na mina a céu aberto, situada no Distrito Mecânico do bairro das Trincheiras (Figura 3 e $5 d$ ).

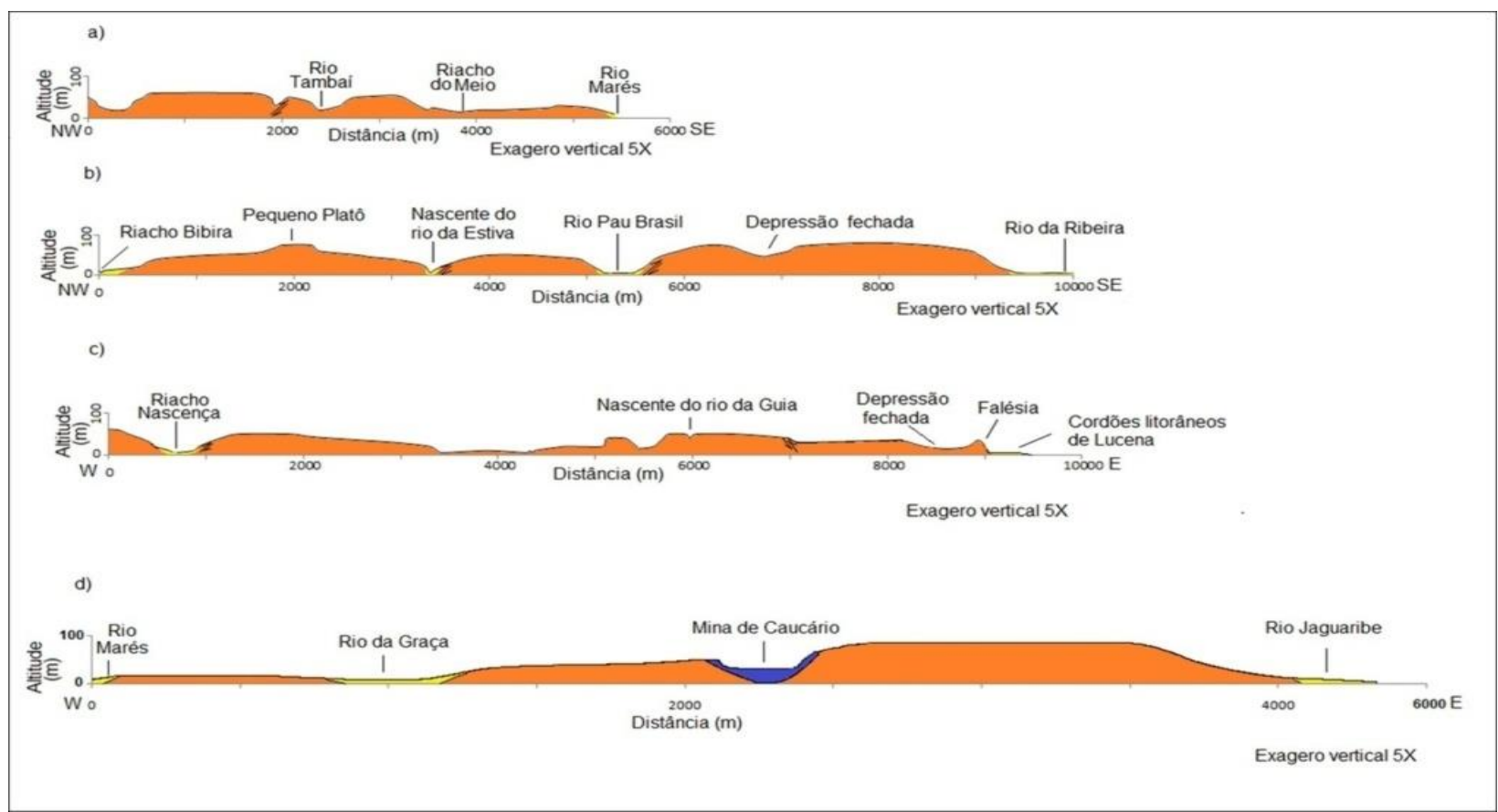

Figura 4 - Perfis topográficos da porção terminal do baixo curso do rio Paraíba do Norte - PB. Fonte: Lavor (2016). Nota: (a) perfil topográfico do tabuleiro litorâneo no município de Bayeux; (b) perfil topográfico do tabuleiro litorâneo no município de Santa Rita; (c) perfil topográfico do tabuleiro litorâneo no município de Lucena; (d) perfil topográfico do tabuleiro litorâneo do Município de João Pessoa. Observar localizações dos perfis na figura 3(linha vermelha).

\subsection{Outras formas de relevo (formas atuais)}

\section{a) Lagunas e lagoas antropogênicas}

As lagunas são comumente encontradas em planícies marinhas e flúvio marinhas, como a de Cabedelo (Figura 3). Elas correspondem às depressões que ocorrem nessas planícies e que, em período chuvoso, armazenam água do lençol freático aflorante. Devido ao intenso processo de urbanização que essa planície enfrenta nos dias atuais, boa parte dessas lagunas foram soterradas, restando apenas um exemplar (Quadro 2a), localizado no bairro do Bessa (João Pessoa). Além das lagunas naturais, também se verificam, na planície de Cabedelo, formas lagunares geradas pela ação humana, como as lagoas da praia do Jacaré (Cabedelo), geradas devido à atividade de extração de areia para a construção civil (Quadro 2b).

b) Bancos arenosos dos recifes costeiros

$\mathrm{Na}$ zona de arrebentação das parias do município de Cabedelo, encontram-se formações rochosas denominadas de recifes costeiros (Figura 3). É nesse trecho que afloram, em marés baixas, bancos de areias conhecidos localmente por Areia Vermelha e Areia Dourada. São acumulações de sedimentos em formato de "coroa", desenvolvida, possivelmente, pelas frentes de ondas quando incidem sobre os recifes. Segundo Miranda (2005), os sedimentos que compõem esses bancos são constituídos por finos e médios grãos de areia associados a fragmentos cascalhosos de origem orgânica (como concha de gastrópodes e fragmentos de algas calcárias), que se acumularam devido às correntes que circulam entre os recifes e a praia da região. Atualmente, esses bancos de areia estão inseridos nos limites da Unidade de Conservação (UC) Parque Estadual Marinho Areia Vermelha (PEMAV), que ocupa uma área de $2,3 \mathrm{~km}^{2}$, distante a $1 \mathrm{~km}$ da praia de Camboinha, em Cabedelo (Quadro 2c e 2d).

\section{c) Barra de Cabedelo}

Durante anos, observaram-se mudanças significativas na morfologia da linha de costa da desembocadura do rio Paraíba do Norte. Guedes (2002) verificou que, na ponta da planície flúvio marinha de Cabedelo, onde se localiza o complexo portuário e o forte de Santa Catarina, houve a progradação da linha de costa para o norte de, aproximadamente, $300 \mathrm{~m}$. Provavelmente, a construção do porto de Cabedelo e, posteriormente, de um molhe (com 1.200 m de extensão) perpendicular à deriva litorânea, tenha interferido na morfodinâmica local. $\mathrm{O}$ contrário ocorreu na planície marinha de Lucena, onde se verificou um intenso processo erosivo. A construção do molhe na banda sul da desembocadura induziu à erosão da praia da ponta de Lucena (praia de Costinha). Com o propósito de conter esses processos e, 
ao mesmo tempo, promover o engorde dessa praia, instalaram-se gabiões na praia de Costinha (Quadro 2e), o que gerou a deposição de sedimentos no interior do canal estuarino, proporcionando a formação de dunas e a progradação da porção frontal da ilha da Restinga (GUEDES, 2002). A própria dinâmica costeira promove alterações nessas áreas e, quando estas sofrem

Quadro 2 - Formas de relevo atuais e antropogênicas.

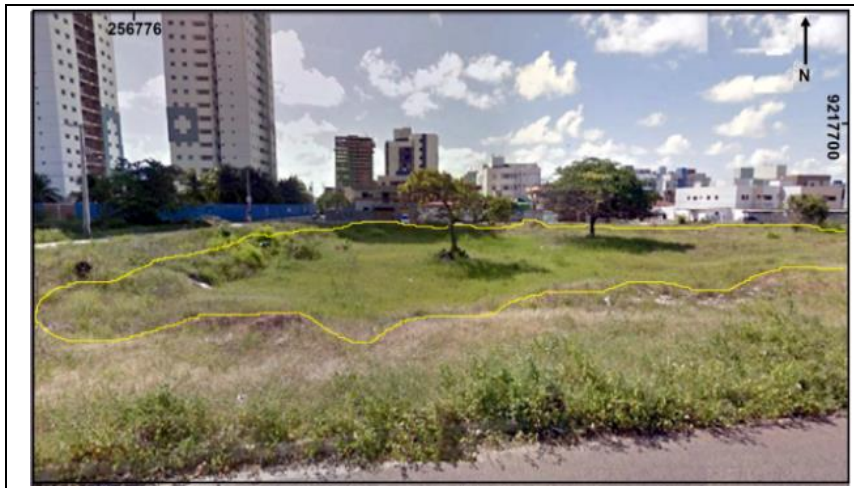

A) Laguna no bairro do Bessa em João Pessoa (linhas amarelas). Aparentemente, encontra-se assoreada e envolta de uma área bastante urbanizada. Fonte: Google (2016).

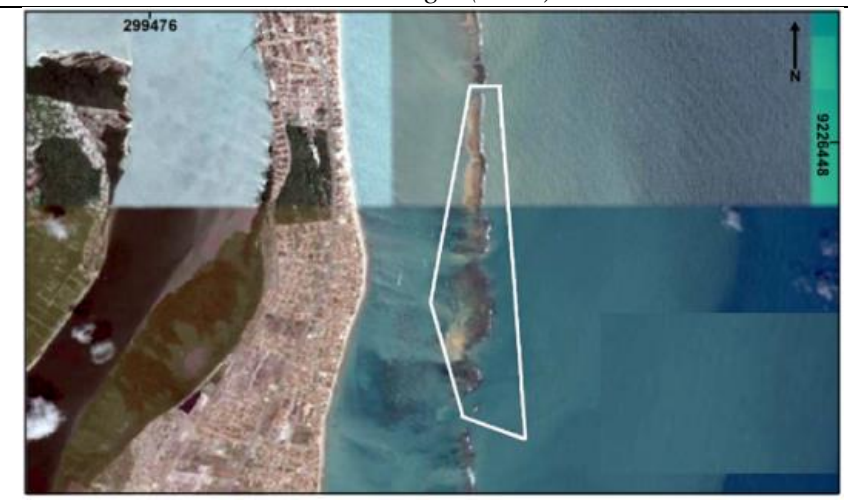

C) Delimitação do Parque Estadual Marinho Areia Vermelha (polígono branco). Na imagem, fica evidente a sinuosidade do ambiente recifal que segue paralelo e quase com a mesma forma da atual linha de costa do município de Cabedelo. Esta observação leva ao entendimento de que essa forma geomorfológica, possivelmente, trata-se de uma paleolinha de costa Fonte: Google (2015). interferências antropogênicas, os processos se intensificam e ao analisar a imagem de satélite de 2015 (Quadro 2f), observam-se novas alterações na morfologia da barra. Verificou-se que, do complexo portuário até a praia, houve uma progradação de, aproximadamente, $300 \mathrm{~m}$ a mais do que o observado por Guedes (2002).

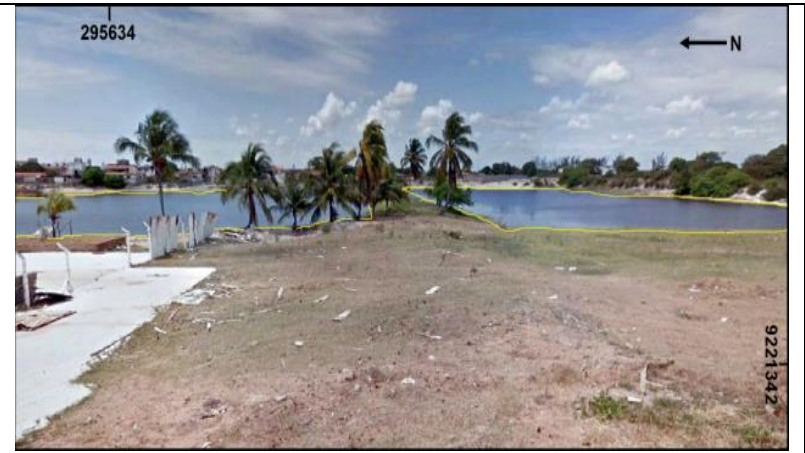

B) Lagoas de origem antropogênicas geradas pela atividade de extração mineral para a construção civil (linhas amarelas), localizada na praia do Jacaré (Cabedelo). Fonte: Google (2016).

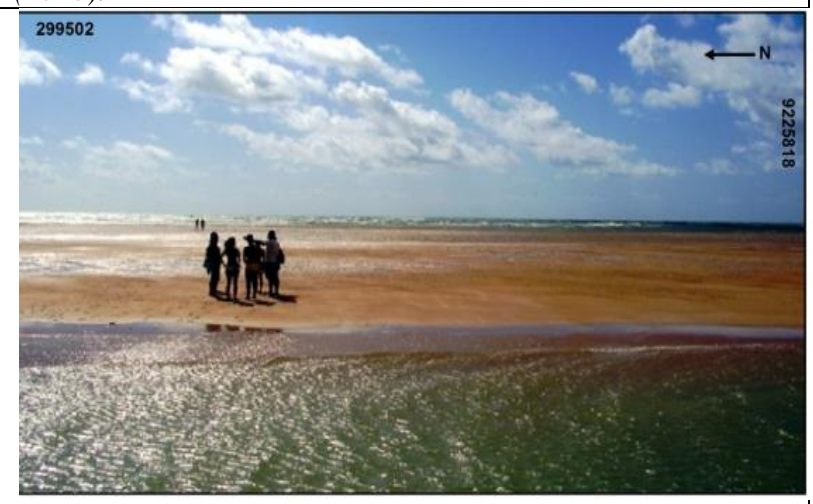

D) Banco de areia localizado no PMAV, em uma maré $0.7 \mathrm{~m}$. Ao redor do banco proliferam-se algas calcárias, regolitos, corais e outras espécies marinhas que emergem em marés a partir de 0.5 m. Fonte: Lavor (2016). 


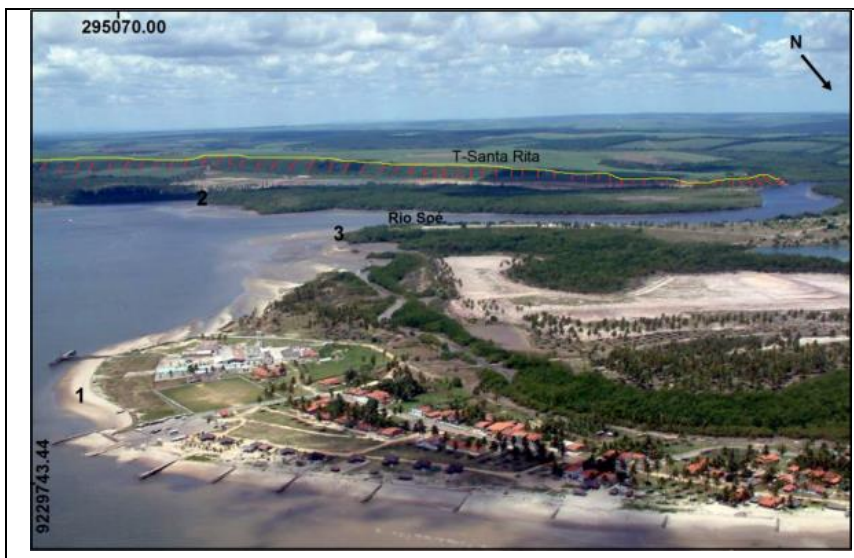

E) Observam-se, na fotografia aérea, as diversas construções de engenharia do tipo molhe (1) na praia de Costinha (Lucena). Ao noroeste da imagem localizam-se o tabuleiro de Santa Rita (linha amarela), trecho da área de Acumulação de colúvio (linhas vermelhas), terraços e planícies flúvio marinha (2) do distrito Forte Velho (Santa Rita) e parte da área de Acumulação da planície flúvio marinha de Lucena. Fonte: Ricardo Paulo, 2002

\section{(d) Depressões fechadas}

As depressões superficiais fechadas correlacionadas aos calcários da Bacia Sedimentar Paraíba são unidades geomorfológicas que podem ocorrer com ou sem a presença de água. Observação em campo e de dados de subsuperfície avaliados por Lavor (2016) aponta que as depressões superficiais fechadas estão relacionadas às dolinas de subsidência lenta presente nos terrenos de rochas calcárias sotopostas à Formação Barreiras. Identificaram-se três depressões superficiais fechadas

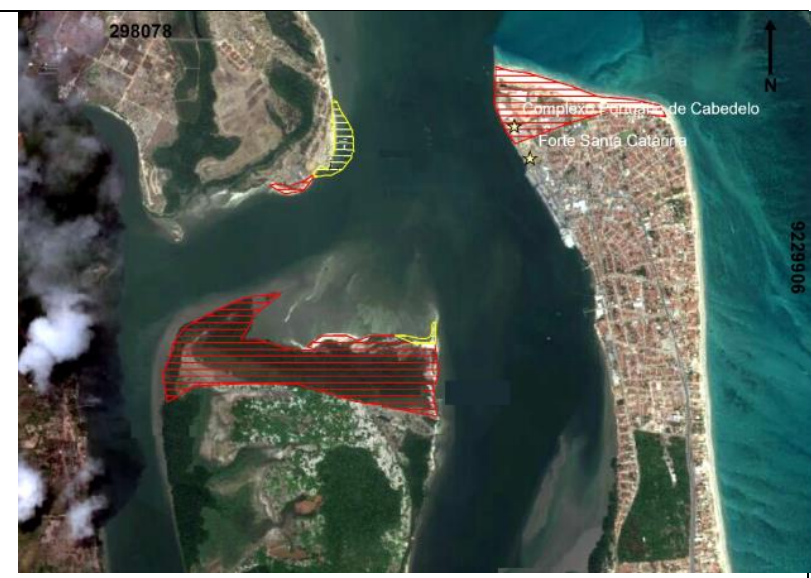

F) As áreas tracejadas foram as que sofreram alterações, sendo que, em vermelho são as de progradação e, em amarelo, setores em processo de erosão. Fonte: Google (2015)
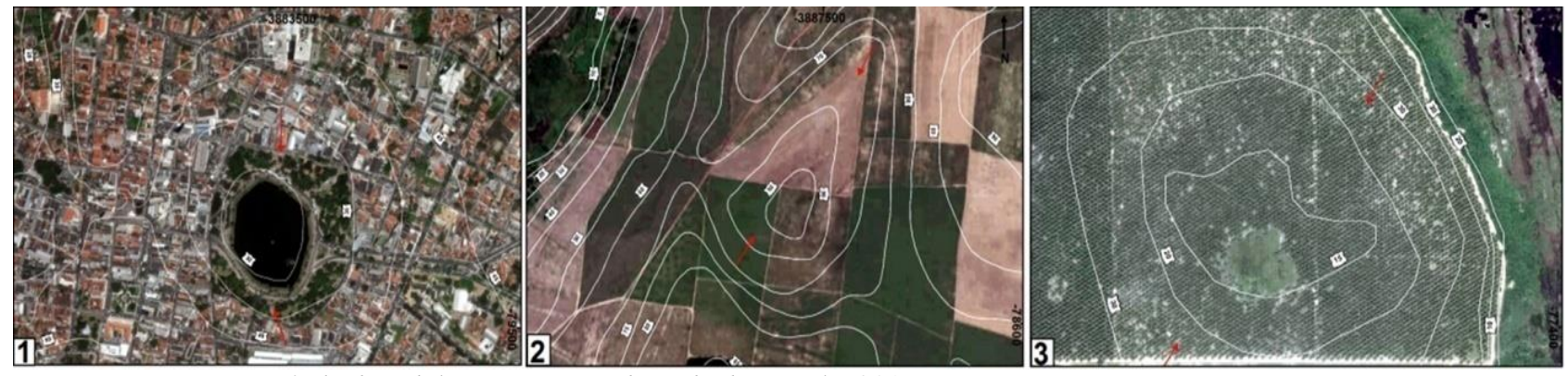

Figura 5 - Depressões fechadas (dolinas). Fonte: Adaptado de Google (2015).

\section{CONSIDERAÇÕES FINAIS}

Os resultados das diversas análises executadas nesta pesquisa mostraram uma nítida relação entre a geologia, por meio de aspectos litológicos e da tectônica, e as condições climáticas, que favoreceram a formação de relevos e rios que modelaram a superfície litorânea, dando origem às planícies, terraços, depressões e elevações de topos quase planos. A dinâmica costeira também participou do modelado da região, contribuindo com a formação de terraços marinhos, falésias, cordões litorâneos, praias e áreas estuarinas.

Boa parte da área estudada encontra-se altamente urbanizada, principalmente aquelas relacionadas às unidades de relevo Atpm na área. A primeira localiza-se no topo do tabuleiro litorâneo do município de João Pessoa, possui uma bacia radial centrípeta com área aproximada de $1,0 \mathrm{~km}^{2}$ e perímetro de cerca de 4,0 km, (Figura, 7-1). A segunda localiza-se no município de Santa Rita e apresenta-se com o contorno oval, diâmetro de $0,52 \mathrm{~km}$ e perímetro de $2,92 \mathrm{~km}$ (Figura 7-2). A terceira localiza-se no município de Lucena e possui uma forma circular, diâmetro de $2,66 \mathrm{~km}$ e perímetro de 0,54 km (Figura 7-3). grau de dinamismo causado pela influência das marés, das ondas e do vento, assim como dos fatores de ordem química e biológica. Por serem zonas de acumulação de sedimentos com uma tendência natural em determinados setores das praias de apresentarem déficit sedimentar, essas áreas necessitam de maior atenção dos órgãos gestores, devido a sua elevada vulnerabilidade. Outra zona bastante alterada é a relacionada à unidade Actpf. No setor sul da área de estudo, essas formas de acumulação estão altamente urbanizadas, enquanto a oeste relacionam-se ao cultivo da cana-de-açúcar. Essa unidade localiza-se entre as vertentes e as áreas denudacionais do tabuleiro litorâneo e nela drenam as águas provenientes do 
aquífero Barreiras, que migram por ressurgências nos sopés das vertentes, possibilitando a dissecação e o afloramento, em alguns trechos, da Formação Gramame. São nesses setores que se localizam as áreas de mineração de rochas calcárias.

Conclui-se, portanto, que compreender o quadro geomorfológico do litoral paraibano é um passo importante para o manejo de suas áreas urbanas e rurais. As técnicas aplicadas na elaboração dos produtos cartográficos do presente trabalho possibilitaram produzir um mapa geomorfológico inédito para a área de estudo. Sendo assim, esses dados podem vir a serem utilizados como base para a elaboração de trabalhos relacionados ao planejamento e ordenamento territorial da porção terminal do baixo curso do rio Paraíba do Norte.

\section{REFERÊNCIAS}

ALHEIROS, M. M.; LIMA FILHO, M; MONTEIRO, F. A. J; OLIVEIRA E FILHO, J. S. Sistema deposicional na Formação Barreiras no Nordeste Oriental. In: CONGRESSO BRASILEIRO DE GEOLOGIA, 35, 1988, Belém. Anais... Belém: SBG, v. 2, p. 753-760, 1988.

BARBOSA, T.; FURRIER, M.; SOUZA, S. A. Antropogeomorfologia do município de Cabedelo - Paraíba, Brasil. Revista de Geografia e Ordenamento do Território, ano 13, p. 59-83, 2018.

BRASIL. Instituto Brasileiro de Geografia e Estatística. Coordenação de Recursos Naturais e Estudos Ambientais. Manual Técnico de Geomorfologia. 2. ed. Rio de Janeiro: IBGE, 2009.

Ministério de Minas e Energia. Companhia de Pesquisa de Recursos Minerais - Serviço Geológico do Brasil. Geologia e recursos minerais do estado da Paraíba. Recife: CPRM, 2002. 142 p. il., 2 mapas. Escala 1:500.000, 2002.

Superintendência de Desenvolvimento do Nordeste. Folhas SB.25-Y-A-VI-3-SE (Cabedelo), SB.25-Y-A-VI-3-SO (Rio Soé), SB.25-Y-C-III-1-NE (João Pessoa), SB.25-Y-CIII-1-NO (Mata da Aldeia) e SB.25-Y-C-III-1-SO (Santa Rita). Recife: Sudene, 1972. 5 Cartas Topográficas. Escala 1:25.000, 1972.

CHRISTOFOLETTI, A. Geomorfologia. 2. ed. São Paulo: Edgard Blucher, 1980.

CORREA FILHO, O. J; ALENCAR, M. L; BARBOSA, J. A; NEUMANN, V. H. Proposta de formalização da formação Tambaba, Eoceno da bacia Paraíba, NE do Brasil. Estudos Geológicos, v. 25, n. 2, p. 61-81, 2015.

EMPRESA BRASILEIRA DE PESQUISA AGROPECUÁRIA. Centro Nacional de Pesquisa de Solos. Manual de métodos de análise de solo. 2. ed. Rio de Janeiro: Embrapa, 1997.

FURRIER, M. Caracterização geomorfológica e do meio físico da Folha João Pessoa - 1:100.000. 2007. 213 f. Tese (Doutorado em Geografia Física) -Universidade de São Paulo, São Paulo, 2007.
FURRIER, M; ARAÚJO, M. E; MENESES, L. F. Geomorfologia dos Tabuleiros Litorâneos no estado da Paraíba. In: SILVA, A. B; GUITIERRES, H. E. P; GALVÃO, J. C (Orgs). Paraíba: pluralidade e representações geográficas. Campina Grande: EdufCG, 2015.

GOOGLE. Google Earth. Disponível em: <https://www.google.com.br/earth>. Acesso em: 26 ago. 2015.

Google Mapas. Disponível em: $<$ https://www.google.com.br/maps>. Acesso em: 10 out. 2016.

GUEDES, L. S. Monitoramento geoambiental do estuário do rio Paraíba do Norte - PB por meio da cartografia temática digital e de produtos de sensoriamento remoto. 2002. $91 \mathrm{f}$. Dissertação (Mestrado em Geodinâmica e Geofísica) Universidade Federal do Rio Grande do Norte, Natal, 2002.

GUERRA, A. T.; GUERRA, A J. T. Novo dicionário geológicogeomorfológico. 6. ed. Rio de Janeiro: Bertrand Brasil, 2008.

LAVOR, L. F. Geodiversidade e sítios históricos na porção terminal do baixo curso do rio Paraíba do Norte. 2016. 174f. Dissertação (Mestrado em Geografia) - Universidade Federal da Paraíba, João Pessoa, 2016.

LAVOR, L. F.; ARAÚJO, M. E. Afloramentos calcários e antigas pedreiras no estuário do rio Paraíba do Norte - PB. Estudos Geológicos (UFPE), v. 26, p. 46-61, 2016.

MARQUES, J. M. Ciência Geomorfológica. In: GUERRA, A. J. T.; CUNHA, S. B. Geomorfologia: uma atualização de bases e conceitos. 7. ed. Rio de Janeiro: Bertrand Brasil, p. 23-45, 2007.

MAIA, R. P.; BEZERRA, F. H. R. Geomorfologia e neotectônica da bacia hidrográfica do rio Apodi-Mossoró - NE/Brasil. Mercator, v. 11, n. 24, p. 209-228, jan./abr. 2012.

MIRANDA, G. E. C.(Org.). Relatório do grupo de trabalho para ampliação do Parque Estadual Marinho Areia Vermelha (Cabedelo-PB). João Pessoa: EdUFPB, 2005.

NEUMANN, V. H. M. L.; GUERRA, N. C; MELO, C. B.; FARIAS, D. J. S.; MENESES FILHO, J. A.; LIMA, F. P. 2014. Carta geológica da folha SB.25-Y-A-V II Cabedelo, escala 1:100.000. Brasília: CPRM, 2014.

RODRIGUES, S. C.; OLIVEIRA, P. C. A. Cartografia do relevo: um estudo aplicado na região oeste de Minas Gerais. Revista Brasileira de Geomorfologia, ano 8, n. 2, p. 37-44, 2007.

ROSS, J. L. S. Geomorfologia Ambiente e Planejamento: $O$ relevo no quadro ambiental cartografia geomorfológica, diagnósticos ambientais. 9.ed.,São Paulo: Editora Contexto, 2014

O registro cartográfico dos fatos geomórficos e a questão da taxonomia do relevo. Revista do Departamento de Geografia (USP), São Paulo, n. 6, p. 17-29, 1992. 
SOUZA, J. O. P. Análise da precisão altimétrica dos Modelos Digitais de Elevação para área semiárida do Nordeste brasileiro. Revista do Departamento de Geografia, USP, v. 30, p. 56-64, dez. 2015.

SUGUIO, K. Geologia do Quaternário e mudanças ambientais. São Paulo: Oficina de Textos, 2012.
. Dicionário de Geologia Sedimentar e áreas afins. Rio de Janeiro: Bertrand Brasil, 1998.

Recebido em: 02/09/2019.

Aceito para publicação em: 23/08/2020. 